\title{
The Relationship Between Côte D’ivoire's Political Situation And Burkina Faso's Maritime Transit Cargo Throughput That Passed Through Ghana
}

\author{
*Tufuor Augustine Kwabena, Mumuni Ishawu, Akrofi Thomas, Bernice Adu-Bekoe \\ Koforidua Technical University, Koforidua Ghana. Department of Liberal Studies \\ Koforidua Technical University, Department of Purchasing and Supply \\ Koforidua Technical University, Department of Student Services \\ *angusttufuor@gmail.com
}

\begin{abstract}
Ghana rose from an insignificant position in 1997/8 to become the topmost maritime transit corridor for landlocked countries in West Africa and particularly for Burkina Faso around 2006. Since then, Ghana's transit corridor has, generally, been recording a declining trend in the yearly percentage throughput of Burkina Faso's maritime transit cargo that is transported along it. Popular opinion in the transit business in West Africa suggests a negative relationship between the level of Côte d'Ivoire's political stability and Burkina Faso's maritime transit cargo throughput that is transported along Ghana's transit corridor. This work, using data drawn from 1998,2000 and 2002-2014 investigated the empirical veracity of such an opinion. Data were sourced from World Governance Indicators and also through questionnaires that were administered to a sample drawn from five major stakeholder official institutions involved in transit trade in Ghana. The study found a significant negative relationship between Côte d'Ivoire's political stability rank and Burkina Faso's maritime transit cargo throughput that was transported through Ghana's corridor over the specified period. The study, among others, recommends a reduction in the number of transit check points and the associated delays and bribery along Ghana's road corridor so as to make it more efficient and competitive in West Africa.
\end{abstract}

Keywords: Land-locked country; transit; cargo; throughput; corridor; and 'transitor'

\section{Introduction}

Countries like Burkina Faso which have no maritime coastlines are, generally, referred to as 'landlocked states' (LLSs). LLS must necessarily transport its sea borne cargo through the territory or corridor of another country (O'Connell, 1965), the latter of which is generally referred to as 'transit state' (TS) (Uprety, 2006). Transporting one's transit cargo throughput, via the corridor of another state, has cost and benefits to both LLSs and TSs. Generally, businesses which serve as importers/exporters (shippers) or freight forwarders or inland transporters of transit goods, which this study has coined the term 'transitors', will opt to use transit corridors that are efficient so that they can minimize cost and maximize profits.

In West Africa (WA), until around 1999, a major part of the LLSs' maritime transit cargo throughput was transported along Côte d'Ivoire's (CIV's) corridor (Adjavon, 2008; Luguje, 2009; United Nations Conference on Trade and Development [UNCTAD], 2007). It is estimated that more than $50 \%$ of the total maritime transit cargo throughput of LLSs in WA was conveyed through CIV's corridor. The other maritime corridors in WA handled the rest of the transit cargo. Notably, these were Benin (19\%), Togo (17\%), Senegal (11\%) and one percent in the case of Ghana $(\mathrm{GH})$ (Adjavon, 2008; UNCTAD, 2007).
Several factors worked to CIV's benefit, prior to 1998. These include, for instance, the strategic geographical location of its main port at Abidjan (Abidjan Port Authority [APA], n.d.; UNCTAD, 2007). Also its efficient infrastructure, state-of-theart equipment and the calibre of companies that were operating at its port (APA, n.d.). Being a Francophone country like all the three LLSs in WA gave and still presents CIV an added advantage over GH (Ghana Ports and Habours Authority [GPHA], 2007). Also, within the sub-region, CIV then had a relatively stable political system and a generally vibrant economy. These, made it far easier, quicker, cheaper, safer and more reliable for transit cargo to be conveyed through CIV's corridor than it was for any other TS with a maritime port in WA. In 1998, however, CIV experienced some socio-political upheavals. The upheavals, subsequently, culminated into the December, 1999 coup d'état and the subsequent political instability (PI) that the country suffered.

There is a replete of literature on empirical studies which indicate some linkage between conflicts or violence or PI on one hand and several socio-economic variables such as health, education, investment, illiteracy, human development index (HDI), income and economic growth (for instance, refer to: Collier, Hoeffler \& Rohner, 2009; Kim \& Conceicao, 2010). 
The relationship between PI and trade, however, remains largely unexplored; also the few studies that attempt an integration of political variables into standard trade models have focused mainly on total trade with no explicit attention to the potential impact of PI in foreign markets (Awokuse \& Gempesaw, 2005). Generally, the relatively few studies on the relationship between trade and PI show a non-unidirectional pattern; PI affects trade and vice versa.

Alesina \& Rodrik (1994), Barro (1991), and Pearson \& Tabellini (1994) all indicate a negative relationship between PI on one hand and economic growth and trade on the other. Political instability decreases productivity and income and thus in the long run leads to an inability to pay for imports (Alesina \& Rodrik, 1994; Barro, 1991; Pearson \& Tabellini, 1994). Gonzalez (2003) and Grossman \& Kim (1996) also note that conflicts divert resources from productive to unproductive activities. Conflicts, it is also argued, makes returns to investments in physical and human capital insecure (LloydEllis \& Marceu, 2003) and crowds out investment in productive activities in favour of military spending (Derger \& Sen, 1983). Also commenting on the issue, De-Soysa (2002) and Hegre, Gissinger \& Gleditsch (2003) posit that, in the long run, trade promotes domestic political stability and avoidance of violence (PSAV) and that they do not find any evidence to the contrary. Collier \& Hoeffler (2001) and Gleditsch \& Gissinger (1999), however, present two diametrically opposing views regarding the relationship between PI and trade. They contend that trade that consists of a high share of primary exports can be disruptive to PSAV whilst exports of manufactured goods create more equality and peace and thus stability.

In the case of CIV, for instance, its PI had significantly negative ramifications on the maritime traffic flows at the Abidjan Port (APA, n.d.). Some of the ramifications spilled onto its transit trade industry thereby making its corridor relatively unsafe and thus uncompetitive to transitors (UNCTAD, 2007). Since the 1999 coup in CIV, several TSs in WA that have maritime ports have made significant efforts to enhance infrastructure, institutions and the legal regime needed to secure and expedite the flow of transit traffic that passes along their respective corridors to and from LLSs (Adjavon, 2008). One of such countries that has made an appreciable investment in its transit trade sub-sector and has also benefited immensely from the 1998/1999 socio-political unrest or instability in CIV is GH (GPHA, 2007; Luguje, 2009; UNCTAD, 2007). This is particularly true with reference to maritime transit cargo to and from Burkina Faso (BF). As a result, the total yearly maritime transit cargo throughput of LLSs in WA that was transported along GH's corridor shot up from an insignificant one percent in 1997 to about 26\% in 2004 (Luguje, 2009). Comparatively, with respect to BF's transit throughput, GH's corridor performed even much better. On the average, $31 \%$ of BF's maritime transit throughput was transported along GH's corridor over the period 2004 to 2007 (Luguje, 2009).

All the sources cited above and many more, with respect to the nature of the relationship between PI and some other economic variables, generally, draw data from variables that pertain to the same country. In the view of the researchers of this current study, the fact that PI or PSAV in one country could spill over either positively or negatively on a neighbouring country calls for studies that deviate from the former which has been the norm to the latter direction. This current work attempts that. Its uniqueness, as compared to the others that have been cited, lies in the fact that it correlates the level of PSAV in a given country with the cargo throughput of a second country that is transported through the corridor of a third country.

Political stability/instability is a governance issue. And in the opinion of Kaufmann, Kraay \& Mastruzzi (2010, p. 4), governance consists of "the traditions and institutions by which authority in a country is exercised." It includes the: process used to select, monitor and replace governments; government's capacity to effectively formulate and implement sound policies; and respect of both the citizens and state for the institutions that govern economic and social interactions among them (Kaufmann et al., 2010). Court, Hyden \& Mease (2002) opine that unlike some measurements in economics or social development fields, the measurement of governance faces several challenges; in view of this, some people even argue that it cannot be measured. Kaufmann, Kraay \& Mastruzzi (2005) and Kaufmann (2008), however, disagree and argue that if governance were non-measurable it would be impossible to tell whether the governance situation in a given country is improving or deteriorating over a given period of time. Kaufmann et al. (2005, intro, para 1) buttresses this argument with a succinct quotation which they attribute to Lord Kelvin: "If you cannot measure it, you cannot improve it."

Currently, there are several data sources on governance. This study, however, draws its data specifically from the world governance indicators (WGI) as reported by Kaufmann, Kraay \& Mastruzzi (2015). Apart from 1997, 1999 and 2001, the 2015-year WGI has data that span the period 1996 to 2014.The WGI data source was chosen by this work because the survey methodology used by Kaufmann and his colleagues is robust. For instance, the surveys are carried out on 31 data sources and from 25 organizations and they capture the views of tens of thousands of stakeholders; the generated results therefore express the views of a wide spectrum of respondents that include households, firms and public officials in 213 countries (Kaufmann, Kraay \& Mastruzzi, 2009). The WGI is 
also one of the most useful, credible (Court et al., 2002) and largest on-line data source. Additionally, WGI are the most widely used by policy makers and researchers to study causes and consequences of good governance (Kaufmann et al., 2005). Also, unlike most governance and other data sources, WGI reports explicit margins of error for each indicator and for each of the countries studied (Kaufmann, 2008).

The WGI data source has six major governance indicators and each is generally, scored from -2.50 to 2.50; these, when converted to percentile ranks, correspond in ranges from zero to 100 , respectively. Negative scores translate into percentage ranks that fall below 50 whilst positive scores translate into ranks greater than 50. Among the indicators measured are: rule of law; voice and accountability; and government effectiveness. The others are: regulatory quality; control of corruption; and political stability and absence of violence (PSAV). The latter indicator (PSAV) is what is of concern to this study.

In spite of the tremendous gains made around 2006, current reports coming up show that GH's transit corridor is, apparently, losing some grounds to some competing TSs in WA with regard to its yearly percentage share of especially BF's maritime transit cargo throughput. Notably, among the competing TSs, is CIV. Theoretical or logical reasons have been assigned for this revealing trend. In some circles the decline has been attributed to the improvement in CIV's political situation. Luguje (2009), for instance, intimates that GH's corridor would most likely lose majority, if not all, of its present BF's maritime transit traffic to CIV when the political situation in the latter country improves.

Explicitly or implicitly, Luguje's opinion, like other similar opinions, suggests a strong relationship between the political situation in CIV and the yearly maritime transit cargo throughput of $\mathrm{BF}$ that is transported along GH's transit corridor. This work, relying on empirical data, ascertains the veracity of this opinion. Specifically, it investigates the nature of the relationship between the level of PSAV in CIV and the yearly maritime transit cargo throughput of $\mathrm{BF}$ that was transported along GH's transit corridor from 1998 to 2014. The work also proffers some suggestions on how to improve the competitive edge of GH's transit corridor in the Burkinabe transit cargo business.

In line with the specified statement problem under investigation, the following hypotheses were proposed and tested:

Null hypothesis $\left(\mathrm{H}_{\mathrm{O}}\right)$ :

There is no significant relationship between the level of the PSAV in CIV and the yearly throughput of BF's maritime transit cargo that was transported along GH's corridor over the period 1998-2014. (i.e. $\mathrm{H}_{\mathrm{O}} \rho=0$ )
Alternative Hypothesis $\left(\mathrm{H}_{\mathrm{A}}\right)$ :

There is a significant relationship between the level of the PSAV in CIV and the yearly throughput of BF's maritime transit cargo that was transported along GH's corridor over the period 1998-2014. (i.e. $H_{\mathrm{A}} \rho \neq 0$ )

The following research question was also formulated to guide the study in its analysis:

What policy measures should be put in place in order to make GH's corridor more efficient and thus very competitive in the conveyance of BF's maritime transit cargo throughput?

\section{Methodology}

This work is a cross-sectional survey. It collected data from two major sources: Kaufmann et al.'s (2015) WGI and five key official institutional stakeholders in the transit business in Ghana. The latter were: Customs Excise and Preventive Service (CEPS); Ghana Shippers' Authority; Ghana Ports and Harbours Authority (GPHA); Burkina Faso Chamber of Commerce (BFCC), Ghana; and Burkina Faso Shippers' Council (BFSC), Ghana. One person was sampled from each of the five institutions in question. In view of the fact that the information needed was the official data of the specified institutions, the study opted to use the purposive sampling method to select its sample. In each case, the respective Head of Department in charge of Research and Monitoring Department or his/her representative was sampled. In the view of the researchers these were the best placed staff members in their respective organizations to provide the type of information needed by the study.

The research tool that was used to collect data from the five sampled staff members was the questionnaire. Apart from background information the questionnaires solicited two major types of information: the yearly maritime transit cargo throughput of $\mathrm{BF}$ that was transported along GH's transit corridor from 1999 to 2014 and suggestions on how to improve efficiency along GH's transit corridor. The information gathered from the 2015-year WGI data source was the yearly percentile rank or level of CIV's political stability and avoidance of violence for 1998; 2000; 2002-2014. The latter source of data was sourced electronically on-line (i.e. from the internet). Data collected have been given a descriptive analysis, generally. Some too, as appropriate, have been summarized and presented in the form of graphs and tables. The software that was used to calculate the study's correlation coefficient and also to draw the graphs is MS Excel.

\section{Results and Discussions}

The yearly maritime cargo throughput of Burkina Faso's that was transported along Ghana's transit corridor from 1998 to 2014 is shown in Graph 1. Note that, apart from the year 1999 and 2005, the cargo throughput depicts a rising trend from an initially very low figure of 15,774 metric tonnes in 1998 to a 
peak figure of 549,486 in 2006 . Thereafter, the yearly cargo throughput declined continuously to reach 255,062 metric tonnes in 2010. In 2011 the throughput rose to 427,439 metric tonnes; it, however, declined the following year to 413,117 metric tonnes. The throughput for 2013 rose to 422,756. It increased further to 422,989 metric tonnes in 2014.

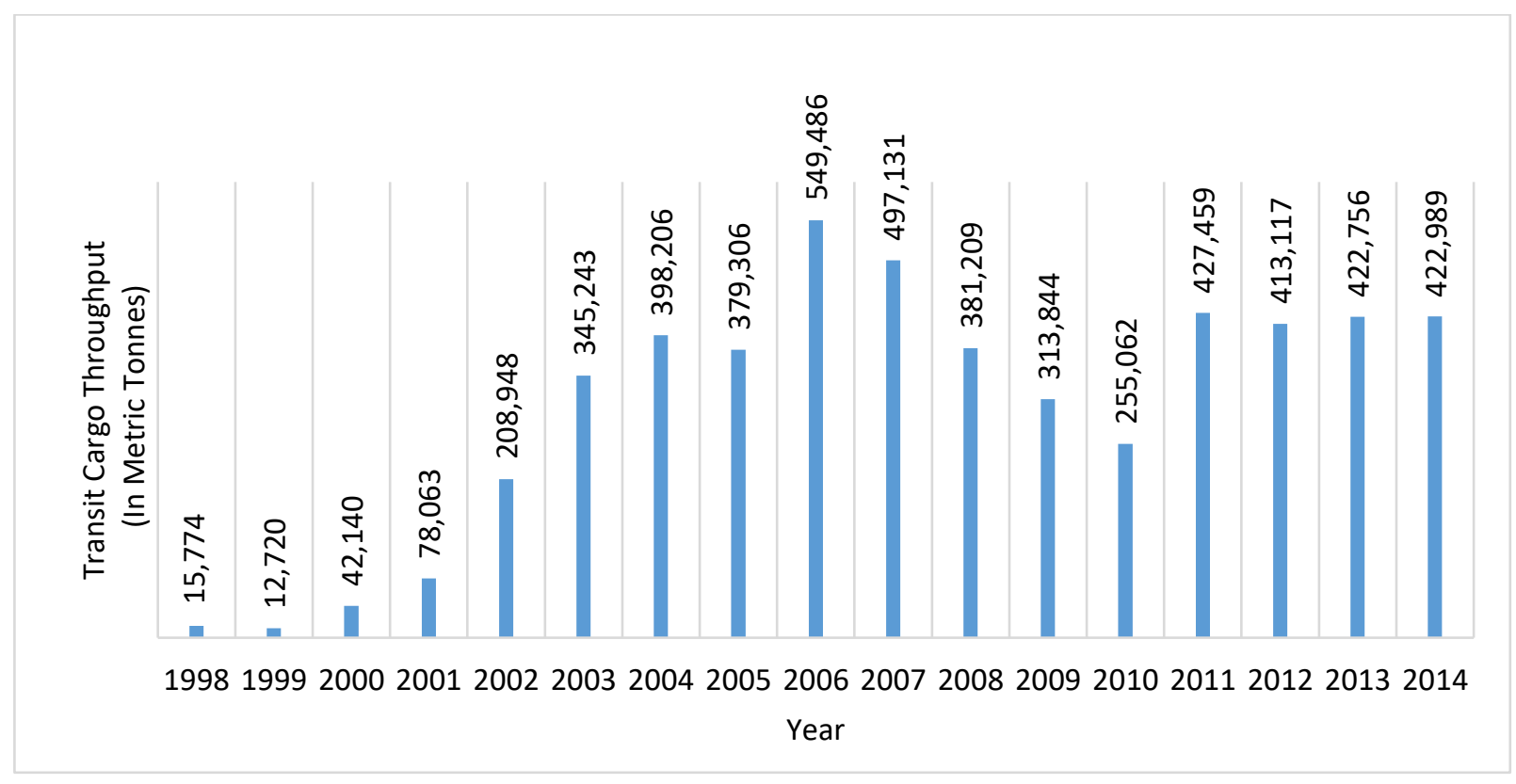

Fig. 1: BF's Yearly Maritime Transit Cargo Throughput transported along GH's Transit Corridor (1998 - 2014).

Source: Responses of respondents and complemented by various documentary sources such as the annual reports and other unpublished documents of the respective agencies of the respondents.

Table 1 exhibits CIV's PSAV percentile rank, score and respective standard error for each of the years under review. In the year 1998, CIV's PSAV percentile rank was relatively good and stood at 34.13 (i.e. a score of -0.26). The percentile rank dropped to 2.4 (i.e. a score of -1.99) in 2002. In 2003, it rose to 4.81 (i.e. a score of -1.84). The figure dropped consecutively the following two years (i.e. 2004 and 2005). It is important to note that CIV's, lowest yearly PSAV percentile rank, as Table 1 exhibits, is 0.96 (i.e. a score of -2.30); the latter PSAV data of CIV was recorded in 2005.

Table 1

CIV's Yearly Level of Political Stability and Absence of Violence from 1998, 2000, 2002-2014.

\begin{tabular}{llcc}
\hline Year & Score & Standard Error & Percentile Rank \\
\hline 1998 & -0.26 & 0.34 & 34.13 \\
1999 & - & - & - \\
2000 & -1.32 & 0.33 & 12.02 \\
2001 & - & - & - \\
2002 & -1.99 & 0.31 & 2.40 \\
2003 & -1.84 & 0.30 & 4.81 \\
2004 & -2.16 & 0.29 & 2.88 \\
2005 & -2.30 & 0.29 & 0.96 \\
2006 & -1.89 & 0.25 & 3.85 \\
2007 & -1.89 & 0.25 & 5.29
\end{tabular}

In Table 1, apart from a few aberrations, like in the year 2010, CIV's yearly PSAV percentile rank (or score) shows a rising trend from the year 2006 to 2013. The respective percentile values for the latter two years are 3.85 (i.e. a score of -1.89) and 17.06 (i.e. a score of -1.02). The corresponding yearly PSAV percentile rank of CIV, for the year 2014, is 12.62 (i.e. a score of -1.01) and thus a decrease when compared to the figure of the immediate previous year. 


$\begin{array}{rrrr}2008 & -1.82 & 0.24 & 7.18 \\ 2009 & -1.28 & 0.24 & 11.37 \\ 2010 & -1.57 & 0.24 & 8.02 \\ 2011 & -1.40 & 0.24 & 8.49 \\ 2012 & -1.26 & 0.22 & 11.37 \\ 2013 & -1.02 & 0.23 & 17.06 \\ 2014 & -1.01 & 0.20 & 12.62\end{array}$

Source: Extracted from Kaufmann et al.'s (2015) WGI data set. Note: WGI has no data for 1999 and 2001.

On the basis of the information provided in Graph 1 (i.e. BF's yearly maritime transit cargo throughput that was transported through GH's corridor) and Table 1 (i.e. CIV's yearly PSAV percentile rank), the calculated sample correlation coefficient (r) is: - 0.5477. The critical " $r$ " value, given a sample (of years) size of $\mathrm{n}=15$ and a level of significance $(\alpha)=0.05$, is: -

0.5139. Graph 2 illustrates this relationship more vividly. Note that the line that best fits all points in the scatter-plot has a negative slope. This, therefore, signifies that there is an inverse relationship between the two variables that have been graphed.

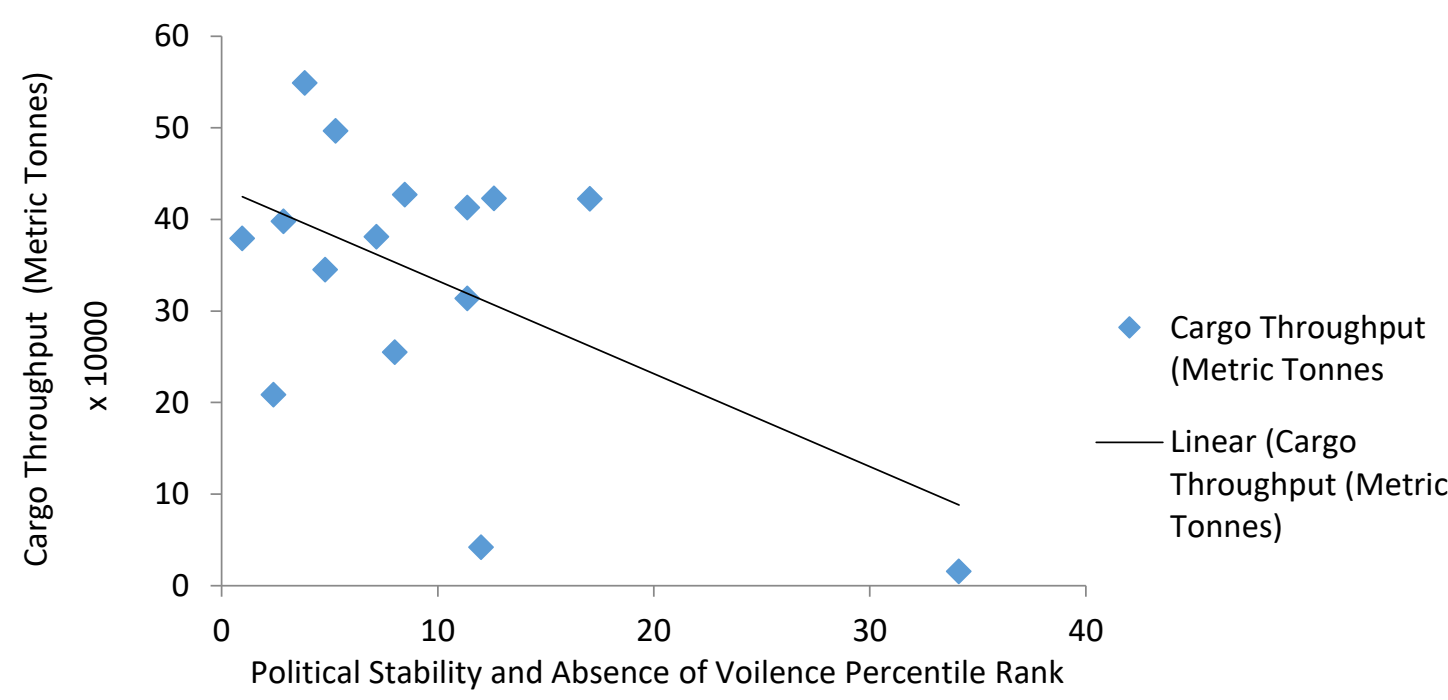

Fig 2 CIV's Political Stability Rank and BF's Maritime Transit Cargo Throughput Transported Along GH's Transit Corridor (1998, 2000 and 2002-2014).

Suggestions were solicited from the respondents regarding how efficiency along GH's transit corridor can be enhanced, with respect to the conveyance of BF's maritime transit cargo throughput. In order to allow for clarity of expressions and also the categorization and an appropriate determination of the frequencies of responses that are similar or connote the same meaning, the researchers have paraphrased the suggestions stated by the respondents and presented them in Table 2.
It was suggested by four (i.e. $80 \%$ ) of the respondents, as can be seen in Table 2, that the number of transit check points should be reduced greatly (i.e. possibly, to a maximum of three) in order to minimize delays and bribery along GH's transit corridor. Three (i.e. 60\%) of the respondents stated each of the following three suggestions as a way to help improve the efficiency along GH's transit corridor: the 
Boankra in-land port project should be speeded up in order to take off some of the pressure at Ghana's two ports (i.e. Tema and Takoradi); the opening and manual examination of transit containers by CEPS at the ports should be minimized to the barest possible level and that adequate tracking devices should be made readily available and accessible to transit truckers so that unwarranted delays at the ports can be minimized; and parking and resting places should be constructed along GH's transit corridor for truck drivers. Less than $50 \%$ of the respondents, as can be seen in Table 2, stated the other listed suggestions. For instance, two (40\%) of the respondents expressed the need to monitor transit operations and to work towards the identification and elimination of unnecessary steps and other causes of excessive delays along the corridor whilst one (i.e. $20 \%$ ) of the respondents stated that there should be some consultations and brainstorming among stakeholder in a bid to help streamline clearance procedures.

Table 2

Respondents' Suggestions on how GH's Transit Corridor to BF can be made more Efficient and thus very Competitive in the West African Sub-region.

- Reduce the number of transit check points (i.e. a maximum of three) and the associated delays and bribery along GH's road corridor.

(80)

- Speed up the Boankra in-land port to take off some of the pressure at GH's two ports (i.e.

Tema and Takoradi).

(60)

- Minimize, to the barest possible level, the opening and manual examination of transit containers by CEPS and to provide adequate tracking devices so to minimize unwarranted delay at the ports.

- Construct parking and resting places along the corridor for truck drivers.

- Establish an appropriate rapid response security task force with hot lines that are accessible at all times to help minimize theft and pilferage of cargo at the ports and highway robbery along the road transit corridor.

(40)

- Operators at the ports should avoid frequent changes in tariffs and procedures and where applicable 'transitors' should be consulted before changes are made.

- Monitor transit operations and work towards the identification and elimination of unnecessary steps and other causes of excessive delays

(40)

- Encourage consultations and brainstorming among stakeholders in order to help streamline clearance procedures.

- Institute proper, transparent and clear procedures for the settlement of claims....

- Institute a national port body to tackle transit related issues. 
The calculated sample correlation value, as noted, is -0.5477 whilst the critical correlation value is -0.5139 . The results indicate that there is a significantly negative relationship between CIV's PSAV percentile rank and BF's yearly maritime transit cargo throughput that was transported through GH's corridor over the years under review (i.e. 1998, 2000 and 20022014). This, therefore, calls for a rejection of the null hypothesis (i.e. $\mathrm{H}_{\mathrm{O}} \rho=0$ ) and the acceptance of alternative hypothesis (i.e. $H_{A}: \rho \neq 0$ ). This empirical finding thus confirms the popular opinion of Luguje (2009) and others that there is an inverse relationship between CIV's level of PSAV and BF's maritime transit cargo throughput that was transported through GH's transit corridor over the period under study.

Luguje's (2009) opinion, it is important to note, suggests a cause-and-effect relationship between the two variables with the causal direction obviously running from CIV's PSAV to BF's maritime transit cargo throughput that was transported through GH's transit corridor. It is worth to point out that, unlike Luguje's (2009) implied opinion, the findings of the current work do not, necessarily, indicate that there is a causeand-effect relationship between the two variables correlated. Such a definite or categorical statement would require a statistical analysis like a regression which does not fall within the purview of the current work under discussion. A future study in that direction would therefore be invaluable.

Several reasons could be deduced to explain the inverse relationship between the two variables correlated, assuming that there is a cause-and-effect relationship which is such that it runs from CIV's PSAV to BF's maritime transit cargo throughput that was transported through GH's transit corridor. Gonzalez (2003) and Grossman \& Kim (1996) do note that conflicts divert resources from productive to unproductive activities. Derger \& Sen (1983) also assert that PI crowds out investment in productive activities in favour of military spending whilst, according to Lloyd-Ellis \& Marceu (2003), conflicts make returns to investments in physical and human capital insecure. Generally, the reverse would be true with respect to the three views expressed above. These imply that a worsening of CIV's PSAV will, other things constant, worsen its security and thus encourage capital flight from its economy. Given the above, CIV's transit corridor would become less efficient and thus uncompetitive within the subregion. As a result, the other TSs that have maritime ports would appear to be, relatively, more efficient in the eyes of 'transitors' than was previously the case. Since 'transitors' are in business to make profits they would, rationally, relocate to the other maritime transit corridors like GH which they now regard as being comparatively more efficient and competitive than CIV. Implicitly, holding other things constant, an improvement in CIV's PSAV would work in the opposite way and thus lead to a decline in BF's maritime transit cargo that is transported through the corridors of TSs like GH which have maritime ports.

The latter scenario could possibly account for the recent declining competitiveness of GH's transit corridor. This view, it is important to note, should not be overstretched. This is because it could also be possible that the improvement in CIV's PSAV constitutes a screen beneath which is hidden a worsening of some transit conditions along GH's corridor. Thus, GH's transit corridor could possibly be losing grounds because it is not sustaining the momentum which initially won it so much patronage from Burkinabe shippers. If the political situation in CIV therefore becomes static for some years and transit conditions in GH get worse the latter country would, in relative terms, lose some of its transit trade business to the former. It is in view of this that there would be the need to take a critical look at the transit trade sub-sector to determine what $\mathrm{GH}$, as a TS, is not doing right so that the actual fundamental problems would be found and the appropriate corrective measures instituted before it is too late. This is because with respect to rational 'transitors' the bottom line is that they are in business to make profit and would therefore tend to prefer transit corridors that are more efficient.

The transit business generates employment, income and government revenue to the economy of GH and 'transitors' would normally prefer transit corridors that are safe and efficient. It is in view of this that all suggestions that can help to improve efficiency and thus competitiveness along GH's corridor must be given the serious attention they deserve. In line with this and as suggested by the respondents, measures would have to be put in place to facilitate transparency in transit processes and procedures. The latter would, possibly, require measures like mandatory time bench-marks which would have to be reviewed constantly in line with the world's best practices in the industry. Transit processes and procedures, as much as possible, would also have to be computerized to minimize the excessive human interfaces that encourage bribery along the corridor. Additionally, the numerous transit check points along GH's road corridor would have to be reduced to a maximum of about three and people caught in acts of bribery would have to be punished appropriately to serve as a deterrent to others.

Ghana's transit corridor could be made more attractive and competitive by further enhancing the security network along it. For instance, GPHA and the appropriate security agencies could institute, along GH's transit corridor, a rapid response security task force with contact phone lines that are accessible at all times to 'transitors'. Also appropriate parking/rest points would have to be set up at vantage points along the corridor so that truckers can have some requisite respite without fear of attacks and robbery whilst they are resting. Clear and transparent procedures would have to be instituted to facilitate the settlement of transit claims where they arise. Also with respect to helping to improve safety, and to some extent 
minimize transit time and cost along GH's transit corridor, government would have to endeavour to improve the transit infrastructure.

Regarding the latter, as a medium to long term measure or program, an extension of rail transport to northern $\mathrm{GH}$ and the completion of the Boankra Inland Port Project would, for instance, minimize the use of the so many dilapidated and inefficient trucks currently servicing the transit trade business in GH. Government, it is recommended, should use appropriate build operate and transfer (BOT) and other relevant concessional packages to attract both domestic and foreign private sector and bilateral/multilateral governmental investment to facilitate the provision of such facilities.

Contemporary business practices and ethics require participation of, and consultation among all relevant stakeholders. This is not different when it comes to the issue of an efficient transit trade. It is in view of this that there would be the need for the official operators and policy formulators like central government, GPHA and CEPS and other private operators like the shipping lines, the stevedoring and stripping companies to frequently involve 'transitors' with respect to the determination of transit related documentation, prices and processes or procedures. Unilaterally orchestrated frequent changes in procedures and prices by some sections of the stakeholders should not be entertained in the industry. When prior and adequate notification has not been given, such changes make it difficult for 'transitors' to effectively plan ahead. In view of this such practices would have to be discouraged along GH's corridor. Additionally, once in a while, government agencies like CEPS would have to conduct educational programmes for its staff members regarding the importance of transit trade to the economy of GH. During the programs, responsibilities of CEPS's officials as transit trade facilitators and the rights and obligations of 'transitors' in the transit business should be spelt out clearly to CEPS officials. In order not to sabotage some of the above measures, it is also recommended that the condition of service of governmental agencies like CEPS and Police Service be reviewed once in a while and appropriately enhanced to motivate them to honour effectively and efficiently their transit responsibilities.

\section{Conclusions}

The study found that there is a significantly negative relationship between the respective two variables which were tested and thus confirms the popular opinion of Luguje and others that there is an inverse relationship between CIV's level of PSAV and BF's maritime transit cargo throughput that was transported through GH's transit corridor over the period under review. In order to be more competitive and thus increase or even maintain its percentage share of BF's maritime transit cargo business, $\mathrm{GH}$ would have to continually improve efficiency along its transit corridor. In line with this, efforts would have to be made to enhance the existing transit procedures, processes and facilities along GH's transit corridor. The recommendations in this direction include: reducing the number of transit check points, speeding up the construction of the Boankrs in-land port, the cconstruction of parking and resting places along the corridor for truck drivers and a monitoring of transit operations and work in order to identify and also eliminate all unnecessary steps and other causes of excessive delays.

The WGI data source has no PSAV data for the years 1999 and 2001 (Kaufmann et al., 2010). Organization for Economic Cooperation and Development (OECD) has data on CIV's political stability for the respective years, however, the units of measurement are different from that of WGI's data source. Also, OECD's data source provides no basis to convert its data to the form used by WGI. Therefore, the correlation analysis of this study did not include the two years in question. It is important to note that the respective data for the two years, if they were available and taken into consideration, could possibly have changed the results of the correlation analysis that have been presented in this study. Also it is possible that a bigger sample size would have yielded more suggestions on how to make GH's transit corridor more efficient and competitive in West Africa. The latter could, additionally, have altered the percentage-weight or significance attached to each of the listed suggestions that the respondents stated.

In the area of further research, it is recommended that studies should be carried out to determine if there exists, empirically, a causal relationship between CIV's PSAV and BF's maritime transit cargo throughput that is transported along GH's transit corridor; and to ascertain from a broader spectrum of 'transitors' and other stakeholders in the transit business the underlying factor(s) that account for the apparent declining competitiveness of GH's transit corridor in the Burkinabe transit trade business and how to overcome such challenges.

\section{References}

Abidjan Port Authority. (n.d.). Discovering the Abidjan Port. Abidjan, Cote d'Ivoire: Author.

Adjavon, B. (2008). Cordination and harmonization of policies toward an effective transit trade regime in West and Central Africa. In Shipping Review, 10 (3), 2-9.

Alesina, A., \& Rodrik, D. (1994). Distributive politics and economic growth. In Quarterly Journal of Economics, 109, $465-490$.

Awokusi, T. O., \& Gempesaw, C. M. (2005). Foreign political instability and US agricultural exports: Evidence from panel data. In Economic Bulletin, 6(15), 1-12.

Barro, R. J. (1991). Economic growth in cross section countries. In Quarterly Journal of Economics, 106,407443. 
Collier, P., \& Hoeffler, A. (2001). Greed and grievance in civil war Retrieved from

http://econ.worldbank.org/files/12205 greedgrieva nce 23 oct.pdf.

Collier, P., \& Hoeffler, A. (2004). Greed and grievance in civil war. In Oxford Economic Papers, 56(4), 563-595.

Court, J., Hyden, G. and Mease, K. (2002). Assessing governance: Methodological challenges. In World Governance Survey Discussion Paper, 2nd August, 2002 Tokyo: United Nations University.

Derger, S., \& Sen, S. (1983). Military expenditure, spin-off and economic development. In Journal of Development Economics, 13, 67-83.

De-Soysa, I. (2002). Paradise is a bazaar? Greed, creed, grievance and governance 1989-99. In Journal of Peace Research, 39(4), 395-416.

Gleditsch, N. P., \& Gissinger, R. (1999). Globalization and conflict: Welfare distribution and political unrest. In Journal of World-Systems Research, 5(2), 274-300.

Gonzalez, F. (2003). Effective property rights, conflict and growth. Vancouver, BC: University of British Columbia.

Ghana Ports and Harbours Authority. (2007). Ghana ports bandbook, 2007-2008. Colchester Essex, UK: Land and Marine Publishing.

Grossman, H., \& Kim, M. (1996). Predation and accumulation. In Journal of Economic Growth, 1(3), 333351.

Hegre, H., Gissinger, R. \& Gleditsch, N. P. (2003). 'Globalization and Internal Conflict' in G. Schneider, K. Barbieri, \& N.P. Gleditsch, (eds.). Globalization and Conflict. Boulder: Rowman and Littlefield. pp 247- 272.

Kaufmann, D. (2008). Challenging orthodoxy on governance and corruption: Lessons from worldwide empirics. Retrieved from http://www.govindicators.org
Kaufmann, D., Kraay, A., \& Mastruzzi, M. (2005). Measuring governance using cross-country perception data. Retrieved from http://mpra.ub.uni-muenchen.de/8210/

(2009). Governance matters VIII: Aggregate and individual governance indicators 1996-2008. In Policy Research Working Paper Series 4978, Washington DC: World Bank. Retrieved from http://www.govindicators.org

(2010). The worldwide governance indicators: Methodology, data and analytical issues. World Bank Policy Research Working Paper (5430). Retrieved from

http://papers.ssm.com/so13/papers.cfm?abstract $\mathrm{id}=168213$ $\underline{0}$

(2015). The worldwide governance indicators, 2015 update: Aggregate governance indicators 1996-2014. Retrieved from http://www.govindicators.org

Lloyd-Ellis, H., \& Marceu, N. (2003). Endogenous insecurity and economic development. In Journal of Development Economics, 72(1), 1-29.

Luguje, M. (2009). Ghana's maritime/road corridor as the transit gateway to Burkina Faso, Mali and Niger. In Shipping Review, 11(4), 2-9.

Myrdal, G. (1970). Corruption: Its causes and effects. In A.J. Heidenheimer (ed.) Political Corruption: Readings in Comparative Analysis. New York, NY: Holt, Rinehart, \& Winston.

N'Guessan, N. (2003). Improvement of transit transport in West Africa. UNCTAD 2003/2 Document, Geneva.

O' Connell, D. P. (1965). International law 1. New York, NY: Oceania Publication.

Pearson, T., \& Tabellini, G. (1994). Is inequality harmful for growth? In American Economic Review, 84, 600-621.

United Nations Conference on Trade and Development. (2007). Transport infrastructure for transit trade of the landlocked countries in West and Central Africa: An overview. An UNCTAD Secretariat Report.

Uprety, K. (2006). The transit regime for landlocked states. Washington, DC: The World Bank. 